\title{
Strategi Pengembangan Usaha Produk Tekstil di PT Priangan Sentosa Tasikmalaya, Jawa Barat
}

\author{
Business Development Strategy for Textile Product at Priangan Sentosa, Tasikmalaya West Java \\ Dedi Siswana Kurniadi ${ }^{* 1}$, Rizal Syarief ${ }^{2 \sharp}$, dan Ani Suryani ${ }^{3 \sharp}$ \\ ${ }^{1}$ LPM Equator, Bogor \\ ${ }^{2}$ Departemen Ilmu dan Teknologi Pangan, FakultasTeknologi Pertanian, Institut Pertanian Bogor \\ ${ }^{3}$ Departemen Teknologi Industri Pertanian, Fakultas Teknologi Pertanian, Institut Pertanian Bogor \\ \#Jl. Kamper Kampus IPB Dramaga Bogor 16680
}

\begin{abstract}
ABSTRAK
Industri produk tekstil berperan penting dalam perekonomian Kota Tasikmalaya, karena menyumbangkan $42,1 \%$ terhadap industri pengolahan. Industri pengolahan menyumbangkan $14,6 \%$ terhadap Produk Domestik Regional Bruto (PDRB) Kota Tasikmalaya. Permasalahan yang dihadapi industri produk tekstil adalah kenaikan harga bahan baku, kenaikan upah buruh, masuknya produk impor berharga murah, persaingan ketat dengan perusahaan sejenis dan berkurangnya pesanan dari pembeli. Dalam upaya mempertahankan kelangsungan usahanya diperlukan penyusunan strategi pengembangan usaha. Tujuan penelitian ini adalah menganalisis kondisi internal dan eksternal perusahaan, perumusan alternatif strategi, penyusunan prioritas strategi dan pemilihan strategi pengembangan usaha PT Priangan Sentosa (PS). Hasil Internal Factor Evaluation $(2,692)$ dan External Factor Evaluation $(2,334)$ menempatkan posisi perusahaan pada sel V (perusahaan harus dijaga dan dipertahankan melalui strategi penetrasi pasar dan pengembangan produk). Metode SWOT menghasilkan rumusan strategi: (1) memanfaatkan kompetisi antar pemasok untuk mendapatkan bahan baku dengan harga penawaran terendah, (2) meningkatkan produksi trainingspak dengan memperluas kemitraan, (3) promosi, (4) memperluas daerah pemasaran, (5) mempertahankan mutu bahan baku, (6) meningkatkan mutu produk, (7) membuat pencelupan, (8) perawatan mesin rekayasa mesin; dan (9) pelatihan keterampilan pekerja. Analisis QSPM menempatkan strategi promosi sebagai prioritas utama. Implikasi manajerialnya adalah: (1) Aspek produksi perlu didukung oleh peningkatan skala ekonomi dengan peningkatan kemitraan, pemilihan pemasok, memanfaatkan efek pembelajaran dan pengalaman, (2) Aspek SDM perlu peningkatan keterampilan pekerja, (3) Aspek Keuangan melalui pembayaran kontan dari pembeli dan peningkatan alokasi biaya pemasaran, (4) Aspek Pemasaran melalui penentuan target pasar setingkat grosir, memperluas wilayah pemasaran dan pemeliharaan loyalitas pelanggan, dan (5) Aspek Teknologi melalui restrukturisasi mesin.
\end{abstract}

Kata kunci: produk tekstil, QSPM, strategi pengembangan usaha, SWOT

\section{ABSTRACT}

Textile product industry has an important role in the economy Tasikmalaya City, because contributing $42,1 \%$ to manufacturing industry. Manufacturing industry contributing $14.6 \%$ to the GRDP Tasikmalaya City. The problem faced by the industry of textile products is the increase in raw material prices, rising labor costs, the entry of lower-priced imported products, intense competition with similar companies and reduced orders from buyers. In an effort to maintain the continuity of their business, it is necessary to develop a strategy of business development. The purpose of this study was to analyze the internal and external conditions, the formulation of

\footnotetext{
* Korespondensi:

Jl Raya Sindangbarang No. 197 Bogor. Indonesia 16117; HP 08122263617, Email : dedisis@yahoo.co.id
} 
strategic alternatives, prioritization and selection of strategic business development strategy PT PS. Results Internal Factor Evaluation (2.692) and External Factor Evaluation (2.334) puts the company's position in Cells V (companies should be preserved and maintained through market penetration strategies and product development. Methods of SWOT result formulation of strategies: (1) take advantage of competition among suppliers to obtain raw materials at the lowest offer price, (2) Increasing production by expanding the partnership, (3) promotion, (4) expand the marketing area, (5) maintain the quality of raw material, (6) improve product quality, (7) makes dyeing, (8) machine maintenance and machine engineering (9) labor skills training. Quantitative Strategic Planning Matrix (QSPM) puts the promotion strategy as a priority. Implications of managerial are: (1) Aspects of production need to be supported by increased economies of scale by improving partnerships with other entrepreneurs, supplier selection, take advantage of the effects of learning and experience, (2) Aspects of HR need to increase the skills of workers, (3) Financial Aspects through cash payments from buyers and increased allocation of marketing costs, (4) marketing aspect through targeting the wholesale level market, expand marketing and maintenance of customer loyalty and (5) Aspects of technology through the restructuring of the machine.

Key words: business development strategy, QSPM, SWOT, textile product

\section{PENDAHULUAN}

Peran industri Tekstil dan Produk Tekstil (TPT) dalam perekonomian nasional sangat penting. Selama tahun 2010-2014 dapat menyumbangkan rataan $1,4 \%$ terhadap Produk Domestik Bruto (PDB) nasional, sedangkan tenaga kerja yang terserap dalam tahun 2012 sampai 2014 cukup besar, yaitu rataan $21,2 \%$ dari tenaga kerja industri manufaktur (BPS, 2015).

Industri produk tekstil berperan penting dalam perekonomian Kota Tasikmalaya. Industri ini menyumbangkan $42,1 \%$ terhadap industri pengolahan (Diskop, UMK dan Indag Kota Tasikmalaya, 2016). Industri pengolahan menyumbangkan 14,6\% terhadap Produk Domestik Regional Bruto (PDRB) Kota Tasikmalaya (BPS Kota Tasikmalaya, 2016).

Permasalahan yang dihadapi industri produk tekstil saat ini adalah meningkatnya harga bahan baku akibat melemahnya nilai mata uang rupiah terhadap Dolar Amerika Serikat (USD). Porsi bahan baku dalam struktur biaya industri produk tekstil mencapai 57,7\% (API, 2014). Menurut Irawan dan Suryatoga (2009), porsi biaya terbesar, yaitu pengadaan material (56-58\%). Sebagian besar bahan baku tekstil masih diimpor, selain itu bahan penolong (zat pewarna dan bahan kimia lainnya) meskipun dibeli lokal tapi masih banyak diperdagangkan dalam denominasi USD (API, 2014). Pada industri fiber pangsa biaya bahan baku impor merupakan yang terbesar (Asmara et al., 2013). Melemahnya nilai mata uang ID Rupiah terhadap USD menyebabkan meningkatnya harga bahan baku. Menurut kajian Bank Mandiri (2014) setiap 1\% depresiasi nilai tukar Rupiah akan menyebabkan kenaikan Harga Pokok Penjualan (HPP) emiten industri tekstil dan produk tekstil $6,91 \%$ pada triwulan berikutnya. Selain adanya persaingan diantara perusahaan lokal, persaingan dalam indutri produk tekstil makin ketat, karena masuknya produk impor. Impor TPT Indonesia pada tahun 2013 sebesar USD 8,5 miliar atau tumbuh $4 \%$ lebih tinggi daripada pertumbuhan ekspornya (API, 2014). Permasalahan berikutnya upah buruh yang cenderung naik setiap tahun akibat penyesuaian dengan perubahan Upah Minimum Kabupaten/Kota (UMK). Hal ini berpengaruh terhadap meningkatnya komponen biaya produksi, karena industri produk teksti sifatnya padat karya. Dalam struktur biaya produksi, upah tenaga kerja mencapai $27,1 \%$ (API, 2014). Semua kondisi tersebut berpengaruh kepada kelangsungan industri produk tekstil di Kota Tasikmalaya, termasuk PT Priangan Sentosa (PT PS) sebagai pelaku usaha dibidang produk tekstil berupa pakaian olah raga.

Permasalahan yang dihadapi PT PS adalah: (1) kenaikan harga bahan baku, (2) kenaikan upah buruh, (3) persaingan yang ketat dengan perusahaan sejenis, (4) produk impor berharga murah dan (5) berkurangnya pesanan dari pembeli. Mencermati kondisi tersebut diperlukan penyusunan strategi pengembangan usaha, agar PT PS terus bertahan dan meningkatkan usahanya. Tujuan penelitian ini menganalisis kondisi internal dan eksternal, perumusan alternatif strategi, 
penyusunan prioritas dan pemilihan strategi pengembangan usaha PT PS.

\section{METODE PENELITIAN}

Obyek penelitian adalah PT PS produsen produk tekstil khususnya pakaian olah raga di Kota Tasikmalaya. Waktu penelitian 5 bulan, mulai Agustus sampai Desember 2015. Populasi dalam penelitian ini adalah industri produk tekstil di Kota Tasikmalaya, dan pengambilan contoh menggunakan metode purposive sampling. Contoh yang dipilih adalah PT PS karena merupakan produsen yang melakukan tahapan paling lengkap dalam proses produksi produk tekstil dan dilakukan dalam perusahaan sendiri, memiliki omset cukup besar diantara produsen lainnya dan sudah melakukan pemasaran di tingkat lokal dan regional.

Data yang dikumpulkan terdiri dari data primer dan sekunder. Data primer diperoleh dari PT PS serta pihak eksternal melalui kuesioner dan wawancara mendalam. Penentuan responden dipilih dengan mempertimbangkan kapasitas pengetahuan kondisi perusahaan dan industri produk tekstil. Responden terdiri atas pemilik perusahaan/ Direktur, Bagian Produksi dan Bagian Pemasaran, Ketua Asosiasi Pengusaha Konveksi Kota Tasikmalaya dan DisKop Usaha Mikro Kecil Menengah (UMKM) dan Indag Kota Tasikmalaya. Data sekunder diperoleh dari laporan berkala atau tahunan PT PS, jurnal dan literatur lainnya yang behubungan dengan penelitian.

Pengolahan data dilakukan dengan program MS Office Excel kemudian dianalisis dengan tahapan: (1) tahap masukan meliputi analisis lingkungan internal dan eksternal perusahaan, (2) tahap pemaduan (the matching stage), (3) tahap pemilihan strategi (David, 2011). Pendekatan penelitian disajikan pada Gambar 1.

\section{Tahap Masukan (the input stage) Analisis Lingkungan Internal}

Lingkungan internal perusahaan merupakan sekumpulan sumber daya, kapabilitas dan kompetensi inti. Sumber daya, menurut Barney (1991) meliputi semua aset seperti keahlian, proses organisasi, atribut, informasi dan pengetahuan yang dikuasai oleh perusahaan dan yang menyebabkan perusahaan dapat menyusun dan mengimplementasikan strategi yang meningkatkan efisiensi dan efektivitas. Wheelen dan Hunger (2012) mendefinisikan sumber daya sebagai aset, kompetensi, proses, keahlian atau pengetahuan yang dikendalikan oleh perusahaan. Analisis internal meliputi aspek produksi, operasi, manajemen, permodalan dan keuangan, pengembangan SDM, aspek pemasaran dan distribusi. Alat analisis lingkungan internal adalah analisis rantai nilai (value chain analysis) dan analisis VRIO. Rantai nilai mengidentifikasikan dan menghubungkan berbagai aktivitas strategik di perusahaan (Hansen dan Mowen, 2001). Value Chain Analysis menurut Shank dan Govindarajan (1992) merupakan alat untuk memahami rantai nilai yang membentuk suatu produk. Analisis rantai nilai membagi aktivitas perusahaan ke dalam dua kategori umum, yaitu aktivitas primer (yang terlibat dalam penciptaan fisik produk, pemasaran, pengiriman ke pembeli dan layanan purna jual) dan aktivitas pendukung yang membantu perusahaan secara keseluruhan dengan menyediakan infrastruktur atau input yang memungkinkan aktivitas primer dilakukan secara berkelanjutan (Pearce II dan Robinson Jr, 2014). Menurut Barney (1991), kompetensi suatu perusahaan dapat dianalisis dengan kerangka VRIO, yaitu Valuable (bernilai), Rare (kompetensi langka diantara perusahaan yang ada dan pesaing potensial) Imitable imperfectly (tidak mudah ditiru), Organizational combined capabilities (tidak bisa digantikan karena secara kombinasi melekat di organisasi). Hasil analisis lingkungan internal merupakan masukan untuk analisis selanjutnya yang menggunakan Internal Factor Evaluation (IFE) matrix.

\section{Analisis Lingkungan Eksternal}

Lingkungan eksternal diklasifikasikan menjadi lingkungan umum dan lingkungan industri (Hubeis dan Najib, 2014). Pearce II dan Robinson Jr (2014) membagi tiga sub kategori yang saling berkaitan, yaitu lingkungan jauh (remote environment), lingkungan industri dan lingkungan operasi. Gupta (2013) menyatakan menganalisis lingkungan umum menggunakan analisis Politic-legal Economic Social and Technology (PEST). Analisis lingkungan industri menggunakan Porter's Five forces analysis. Lingkungan industri merupakan tempat perusahaan tersebut bersaing. Kondisi 


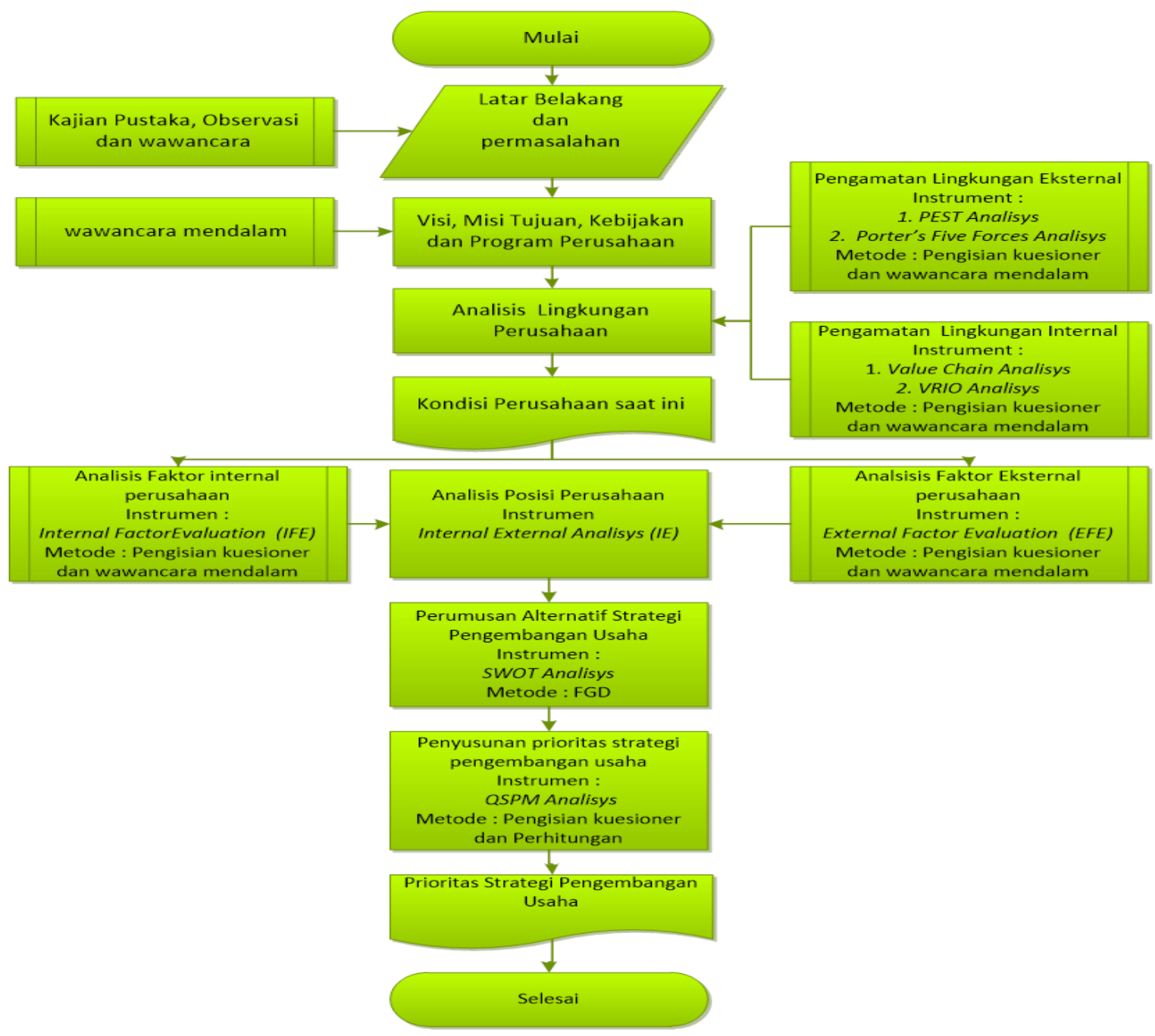

Gambar 1. Pendekatan penelitian

persaingan suatu industri bergantung kepada lima kekuatan dasar, yaitu ancaman pendatang baru, kekuatan tawar menawar pemasok, kekuatan tawar menawar pembeli, produk substitusi dan persaingan antar perusahaan sejenis (Porter dalam Pearce II dan Robinson 2014). Hasil analisis lingkungan eksternal merupakan masukan untuk analisis selanjutnya dengan External Factor Evaluation (EFE) matrix.

2. Tahap pemaduan (The Matching Stage)

a. Penentuan Posisi Perusahaan

Penentuan posisi perusahaan dengan menggunakan model matriks InternalEksternal (Wheelen dan Hunger, 2012).

b. Perumusan Strategi dengan analisis SWOT (Strengths, Weaknesses, Opportunities, Threats)

Perumusan strategi perusahaan menggunakan analisis SWOT yang membandingkan faktor internal (Kekuatan: S dan Kelemah- an: $\mathrm{W}$ dengan faktor eksternal (Peluang: $\mathrm{O}$ dan Ancaman: T). Matriks ini menghasilkan empat set alternatif strategi, yaitu strategi SO, strategi ST, strategi WT dan strategi ST (Rangkuti, 2014).

3. Tahap pemilihan strategi menggunakan Quantitative Strategic Planning Matrix (QSPM)

Menurut David (2011), metode QSPM adalah alat untuk melakukan evaluasi pilihan alternatif secara obyektif, menetapkan daya tarik relatif dari tindakan alternatif yang layak dan memutuskan strategi terbaik. Komponenkomponen utama QSPM terdiri dari: Key Factors, Strategic Alternatives, Weights/Bobot yang diberikan sama dengan yang ada pada matriks EFE dan IFE, Attractiveness Score (AS)/Nilai daya tarik, Total Attractiveness Score (TAS)/Total nilai daya tarik, dan Sum Total Attractiveness Score (STAS)/Jumlah total nilai daya tarik (David, 2011) . 


\section{HASIL DAN PEMBAHASAN}

PT PS merupakan produsen pakaian olah raga jenis trainingspak yang berlokasi di Kota Tasikmalaya. Usaha ini dimulai tahun 1997 di bidang perdagangan pakaian olah raga, kemudian berkembang memproduksi sendiri sambil mengembangkan pasar. Pada tahun 2010 mulai memproduksi kain dan kelembagaannya dibuat berbadan hukum PT PS. Struktur organisasi terdiri atas Komisaris. Direktur, Bagian Produksi, Bagian Pemasaran dan Bagian Keuangan.

\section{Analisis Lingkungan Internal}

\section{Analisis Rantai Nilai}

Rantai nilai kegiatan perusahaan terbagi atas aktivitas primer dan aktivitas pendukung (Gambar 2).

\section{Analisis VRIO}

Analisis VRIO menujukkan kondisi sumber daya dan kapabilitas serta implikasinya (Tabel 1). Berdasarkan diskusi responden ditentukan masing-masing lima peubah faktor lingkungan internal yang paling penting dan berpengaruh (Tabel 2).

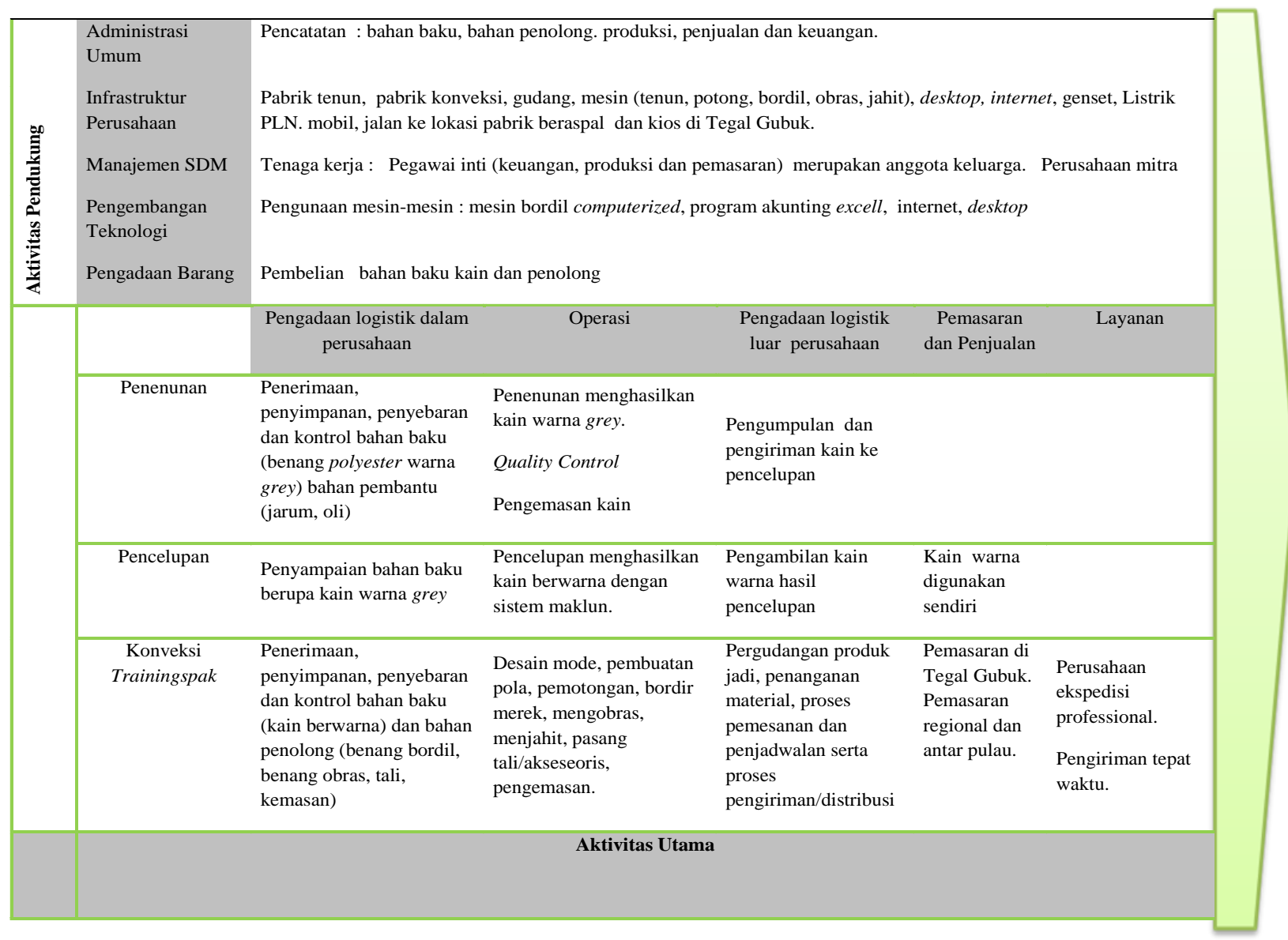

Gambar 2. Rantai Nilai PT PS

Tabel 1. Analisis VRIO PT PS

\begin{tabular}{|c|c|c|c|c|c|c|c|}
\hline $\begin{array}{c}\text { Sumber Daya dan } \\
\text { Kapabilitas }\end{array}$ & V & $\mathrm{R}$ & I & $\mathrm{O}$ & $\begin{array}{l}\text { Implikasi } \\
\text { Kompetitif }\end{array}$ & $\begin{array}{l}\text { Kinerja } \\
\text { Ekonomi }\end{array}$ & Kategori SWOT \\
\hline \multicolumn{8}{|l|}{ Produksi } \\
\hline $\begin{array}{l}\text { Kain bahan baku } \\
\text { trainingspak } \\
\text { diproduksi sendiri }\end{array}$ & ya & ya & ya & ya & $\begin{array}{l}\text { Keunggulan } \\
\text { kompetitif } \\
\text { berkelanjutan }\end{array}$ & $\begin{array}{l}\text { Di atas } \\
\text { normal }\end{array}$ & $\begin{array}{l}\text { Kekuatan dan kompetensi } \\
\text { khusus jangka panjang }\end{array}$ \\
\hline $\begin{array}{l}\text { Pencelupan dengan } \\
\text { sistem maklun }\end{array}$ & ya & tidak & & & $\begin{array}{l}\text { Keseimbangan } \\
\text { kompetitif }\end{array}$ & Normal & Kekuatan atau Kelemahan \\
\hline $\begin{array}{l}\text { Belum ada petugas } \\
\text { QC }\end{array}$ & tidak & & & & $\begin{array}{l}\text { Ketidakunggulan } \\
\text { bersaing }\end{array}$ & $\begin{array}{l}\text { Di bawah } \\
\text { normal }\end{array}$ & Kelemahan \\
\hline
\end{tabular}




\begin{tabular}{|c|c|c|c|c|c|c|c|}
\hline $\begin{array}{c}\text { Sumber Daya dan } \\
\text { Kapabilitas }\end{array}$ & $\mathrm{V}$ & $\mathrm{R}$ & $\mathrm{I}$ & $\mathrm{O}$ & $\begin{array}{l}\text { Implikasi } \\
\text { Kompetitif }\end{array}$ & $\begin{array}{l}\text { Kinerja } \\
\text { Ekonomi }\end{array}$ & Kategori SWOT \\
\hline $\begin{array}{l}\text { Memproduksi dengan } \\
\text { pola Kemitraan }\end{array}$ & ya & tidak & & & $\begin{array}{l}\text { Keseimbangan } \\
\text { kompetitif }\end{array}$ & Normal & Kekuatan atau Kelemahan \\
\hline \multicolumn{8}{|l|}{ Produk } \\
\hline $\begin{array}{l}\text { Produk lengkap } \\
\text { (training spak panjang, } \\
\text { pendek dan baju } \\
\text { kaos) }\end{array}$ & ya & ya & tidak & & $\begin{array}{l}\text { Keunggulan kom- } \\
\text { petitif bersifat } \\
\text { sementara }\end{array}$ & $\begin{array}{l}\text { Di atas } \\
\text { normal }\end{array}$ & $\begin{array}{l}\text { Kekuatan dan Kompetensi } \\
\text { khusus }\end{array}$ \\
\hline $\begin{array}{l}\text { Mutu dan jenis kain } \\
\text { sama/Tidak dicampur }\end{array}$ & ya & ya & tidak & & $\begin{array}{l}\text { Keunggulan kom- } \\
\text { petitif bersifat } \\
\text { sementara }\end{array}$ & $\begin{array}{l}\text { Di atas } \\
\text { normal }\end{array}$ & $\begin{array}{l}\text { Kekuatan dan Kompetensi } \\
\text { khusus }\end{array}$ \\
\hline $\begin{array}{l}\text { Merek AN Sport dan } \\
\text { PAS Sport sudah } \\
\text { dipatenkan }\end{array}$ & ya & ya & ya & ya & $\begin{array}{l}\text { Keunggulan } \\
\text { kompetitif } \\
\text { berkelanjutan }\end{array}$ & $\begin{array}{l}\text { Di atas } \\
\text { normal }\end{array}$ & $\begin{array}{l}\text { Kekuatan dan Kompetensi } \\
\text { khusus jangka panjang }\end{array}$ \\
\hline \multicolumn{8}{|l|}{ Pemasaran } \\
\hline $\begin{array}{l}\text { Kios di Tegal Gubuk } \\
\text { Cirebon }\end{array}$ & ya & ya & tidak & & $\begin{array}{l}\text { Keunggulan kom- } \\
\text { petitif bersifat } \\
\text { sementara }\end{array}$ & $\begin{array}{l}\text { Di atas } \\
\text { normal }\end{array}$ & $\begin{array}{l}\text { Kekuatan dan Kompetensi } \\
\text { khusus }\end{array}$ \\
\hline $\begin{array}{l}\text { Tersedia jalur } \\
\text { distribusi }\end{array}$ & ya & ya & tidak & & $\begin{array}{l}\text { Keunggulan kom- } \\
\text { petitif bersifat } \\
\text { sementara }\end{array}$ & $\begin{array}{l}\text { Di atas } \\
\text { normal }\end{array}$ & $\begin{array}{l}\text { Kekuatan dan Kompetensi } \\
\text { khusus }\end{array}$ \\
\hline $\begin{array}{l}\text { Pemeliharaan } \\
\text { loyalitas Pelanggan } \\
\text { jarang dilakukan }\end{array}$ & tidak & & & & $\begin{array}{l}\text { Ketidak } \\
\text { unggulan } \\
\text { bersaing }\end{array}$ & $\begin{array}{l}\text { Di bawah } \\
\text { normal }\end{array}$ & Kelemahan \\
\hline $\begin{array}{l}\text { Harga jual produk } \\
\text { bersaing }\end{array}$ & ya & ya & ya & ya & $\begin{array}{l}\text { Keunggulan } \\
\text { kompetitif } \\
\text { berkelanjutan }\end{array}$ & $\begin{array}{l}\text { Di atas } \\
\text { normal }\end{array}$ & $\begin{array}{l}\text { Kekuatan dan Kompetensi } \\
\text { khusus jangka panjang }\end{array}$ \\
\hline Pemasaran regional & ya & ya & tidak & & $\begin{array}{l}\text { Keunggulan kom- } \\
\text { petitif bersifat } \\
\text { sementara }\end{array}$ & $\begin{array}{l}\text { Di atas } \\
\text { normal }\end{array}$ & $\begin{array}{l}\text { Kekuatan dan Kompetensi } \\
\text { khusus }\end{array}$ \\
\hline $\begin{array}{l}\text { Konsumen setingkat } \\
\text { grosir }\end{array}$ & ya & ya & tidak & & $\begin{array}{l}\text { Keunggulan kom- } \\
\text { petitif bersifat } \\
\text { sementara }\end{array}$ & $\begin{array}{l}\text { Di atas } \\
\text { normal }\end{array}$ & $\begin{array}{l}\text { Kekuatan dan Kompetensi } \\
\text { khusus }\end{array}$ \\
\hline $\begin{array}{l}\text { Segmentasi pasar } \\
\text { (Konsumen kelas } \\
\text { menengah ke bawah) }\end{array}$ & ya & ya & tidak & & $\begin{array}{l}\text { Keunggulan kom- } \\
\text { petitif bersifat } \\
\text { sementara }\end{array}$ & $\begin{array}{l}\text { Di atas } \\
\text { normal }\end{array}$ & $\begin{array}{l}\text { Kekuatan dan Kompetensi } \\
\text { khusus }\end{array}$ \\
\hline \multicolumn{8}{|l|}{ Layanan } \\
\hline $\begin{array}{l}\text { Pengiriman menggu- } \\
\text { nakan perusahaan } \\
\text { ekspedisi bermutu }\end{array}$ & ya & ya & tidak & & $\begin{array}{l}\text { Keunggulan kom- } \\
\text { petitif bersifat } \\
\text { sementara }\end{array}$ & $\begin{array}{l}\text { Di atas } \\
\text { normal }\end{array}$ & $\begin{array}{l}\text { Kekuatan dan Kompetensi } \\
\text { khusus }\end{array}$ \\
\hline $\begin{array}{l}\text { Pengiriman tepat } \\
\text { waktu }\end{array}$ & ya & ya & ya & ya & $\begin{array}{l}\text { Keunggulan } \\
\text { kompetitif } \\
\text { berkelanjutan }\end{array}$ & $\begin{array}{l}\text { Di atas } \\
\text { normal }\end{array}$ & $\begin{array}{l}\text { Kekuatan dan Kompetensi } \\
\text { khusus jangka panjang }\end{array}$ \\
\hline $\begin{array}{l}\text { Pengiriman untuk } \\
\text { luar jawa, gratis di } \\
\text { drop sampai jakarta }\end{array}$ & ya & ya & tidak & & $\begin{array}{l}\text { Keunggulan kom- } \\
\text { petitif bersifat } \\
\text { sementara }\end{array}$ & $\begin{array}{l}\text { Di atas } \\
\text { normal }\end{array}$ & $\begin{array}{l}\text { Kekuatan dan Kompetensi } \\
\text { khusus }\end{array}$ \\
\hline $\begin{array}{l}\text { Tidak ada complain } \\
\text { handling }\end{array}$ & tidak & & & & $\begin{array}{l}\text { Ketidakunggulan } \\
\text { kompetitif }\end{array}$ & $\begin{array}{c}\text { Di bawah } \\
\text { normal }\end{array}$ & Kelemahan \\
\hline
\end{tabular}

\begin{tabular}{|c|c|c|c|c|c|c|c|}
\hline \multicolumn{8}{|c|}{ Administrasi Umum dan SDM } \\
\hline $\begin{array}{l}\text { Penggunaan desktop, } \\
\text { program akuntansi, } \\
\text { internet }\end{array}$ & ya & tidak & & & $\begin{array}{l}\text { Keseimbangan } \\
\text { Kompetitif }\end{array}$ & Normal & Kelemahan atau kekuatan \\
\hline $\begin{array}{l}\text { Pendidikan karyawan } \\
\text { bidang keuangan dan } \\
\text { administrasi umum } \\
\text { menunjang pekerjaan }\end{array}$ & ya & ya & ya & ya & $\begin{array}{l}\text { Keunggulan } \\
\text { kompetitif } \\
\text { berkelanjutan }\end{array}$ & $\begin{array}{l}\text { Di atas } \\
\text { normal }\end{array}$ & $\begin{array}{l}\text { Kekuatan dan Kompetensi } \\
\text { khusus jangka panjang }\end{array}$ \\
\hline Kepala bagian pro- & ya & ya & ya & ya & Keunggulan & Di atas & Kekuatan dan Kompetensi \\
\hline
\end{tabular}




\begin{tabular}{|c|c|c|c|c|c|c|c|}
\hline $\begin{array}{c}\text { Sumber Daya dan } \\
\text { Kapabilitas } \\
\end{array}$ & $\mathrm{V}$ & $\mathrm{R}$ & I & $\mathrm{O}$ & $\begin{array}{l}\text { Implikasi } \\
\text { Kompetitif }\end{array}$ & $\begin{array}{c}\text { Kinerja } \\
\text { Ekonomi }\end{array}$ & Kategori SWOT \\
\hline $\begin{array}{l}\text { duksi dan pemasaran } \\
\text { berpengalaman }\end{array}$ & & & & & $\begin{array}{l}\text { kompetitif } \\
\text { berkelanjutan }\end{array}$ & normal & khusus jangka panjang \\
\hline SOP tidak tertulis & tidak & & & & $\begin{array}{l}\text { Ketidakunggulan } \\
\text { kompetitif }\end{array}$ & $\begin{array}{c}\text { Di bawah } \\
\text { normal }\end{array}$ & Kelemahan \\
\hline $\begin{array}{l}\text { Tenaga kerja produk- } \\
\text { si terampil terbatas }\end{array}$ & tidak & & & & $\begin{array}{l}\text { Ketidakunggulan } \\
\text { kompetitif }\end{array}$ & $\begin{array}{c}\text { Di bawah } \\
\text { normal }\end{array}$ & Kelemahan \\
\hline \multicolumn{8}{|c|}{ Pengembangan Teknologi } \\
\hline Mesin tenun bekas & tidak & & & & $\begin{array}{l}\text { Ketidakunggulan } \\
\text { bersaing }\end{array}$ & $\begin{array}{c}\text { Di bawah } \\
\text { normal }\end{array}$ & Kelemahan \\
\hline $\begin{array}{l}\text { Belum memanfaatkan } \\
\text { inovasi rekayasa dan } \\
\text { upgrade mesin tenun }\end{array}$ & tidak & & & & $\begin{array}{l}\text { Ketidakunggulan } \\
\text { bersaing }\end{array}$ & $\begin{array}{l}\text { Di bawah } \\
\text { normal }\end{array}$ & Kelemahan \\
\hline \multicolumn{8}{|l|}{ Pengadaan } \\
\hline $\begin{array}{l}\text { Bahan baku benang } \\
\text { dan penolong diper- } \\
\text { oleh dari pemasok } \\
\text { yang dipercaya dan } \\
\text { mempunyai } \\
\text { hubungan lama }\end{array}$ & ya & ya & tidak & & $\begin{array}{l}\text { Keunggulan } \\
\text { kompetitif } \\
\text { bersifat } \\
\text { sementara }\end{array}$ & $\begin{array}{l}\text { Di atas } \\
\text { normal }\end{array}$ & $\begin{array}{l}\text { Kekuatan dan Kompetensi } \\
\text { khusus }\end{array}$ \\
\hline
\end{tabular}

Tabel 2. Daftar kekuatan dan kelemahan

\begin{tabular}{cl}
\hline \multicolumn{1}{c}{ Kekuatan } & \multicolumn{1}{c}{ Kelemahan } \\
\hline $\begin{array}{c}\text { 1. Kain untuk bahan baku } \\
\text { training spak diproduksi } \\
\text { sendiri }\end{array}$ & $\begin{array}{l}\text { Pencelupan dengan } \\
\text { sistem maklun } \\
\text { berbiaya tinggi }\end{array}$ \\
$\begin{array}{c}\text { 2. Memproduksi training } \\
\text { spak dengan pola ke- } \\
\text { mitraan/sistem maklun }\end{array}$ & Qelum ada petugas \\
3. Mutu kain seragam & $\begin{array}{l}\text { Pemeliharaan loyalitas } \\
\text { pelanggan jarang }\end{array}$ \\
& $\begin{array}{l}\text { dilakukan } \\
\text { 4. Harga jual produk } \\
\text { bersaing }\end{array}$ \\
5. Pemasaran regional & terampil terbatas \\
\hline
\end{tabular}

\section{Analisis Lingkungan Eksternal}

\section{Analisis PEST}

\section{Aspek Politik-Hukum}

Kebijakan pemerintah menarik investor luar negeri di bidang industri TPT dianggap tidak penting oleh pengusaha karena dianggap akan menimbulkan ancaman bagi kelangsungan usaha. Peraturan Pemerintah No. 9/ 2016 tentang tentang fasilitas pajak penghasilan untuk penanaman modal (termasuk industri pakaian jadi) dianggap penting, akan tetapi kebijakan tersebut belum bisa dinikmati oleh pengusaha konveksi. Kebijakan tersebut lebih banyak dinikmati oleh perusahaan besar sekelas garmen.

\section{Aspek Ekonomi}

Melemahnya nilai mata uang Rupiah terhadap US\$ yang mencapai Rp13.000/1 Dolar merupakan aspek sangat penting dan ancaman bagi indutri yang berbahan baku impor termasuk di dalamnya industri TPT. Benang yang merupakan bahan baku kain mengalami kenaikan harga dan menyebabkan naiknya biaya produksi. Berlakunya Masyarakat Ekonomi Asean (MEA) dan ASEAN-China Free Trade Area (ACFTA) dianggap penting dan merupakan ancaman bagi IKM termasuk industri produk tekstil berskala kecil.

Dalam struktur biaya industri TPT biaya bahan bakar dan pelumas mencapai $4,17 \%$ dan merupakan biaya terkecil dibanding biaya lainnya (Asmara et al., 2013). Akan tetapi bagi PT PS kenaikan bahan bakar dan pelumas yang disertai kenaikan listrik dan pajak merupakan aspek sangat penting dan dianggap ancaman bagi perusahaan.

\section{Aspek Sosial}

Meningkatnya partisipasi penduduk Indonesia dalam berolah raga dari $21,76 \%$ tahun 2009 menjadi $24,96 \%$ pada tahun $2012^{1}$ (BPS, 2014) mengindikasikan meningkatnya kesadaran penduduk melakukan olah raga. Kondisi ini merupakan peluang bagi produsen pakaian olah raga. Jumlah penduduk Indonesia mencapai 237.641.326 jiwa (SP tahun 2010, BPS, 2012) merupakan peluang karena merupakan pasar dalam negeri yang potensial. Jumlah penduduk pengangguran terbuka

\footnotetext{
${ }^{1}$ Angka 24,96 \% menunjukkan ada 24,96 orang dari 100 penduduk Indonesia berusia 10 tahun ke atas yang berpartisipasi aktif dalam olah raga (BPS, 2014)
} 
di Kota Tasikmalaya pada tahun 2014 mencapai 15.571 orang (BPS Kota Tasikmalaya, 2015). Ketersediaan tenaga kerja ini merupakan hal yang penting dan menjadi peluang bagi PT PS dalam menjalankan produksinya.

\section{Aspek Teknologi}

Ketersediaan teknologi modern berupa mesin potong, mesin border, mesin obras, mesin jahit dan teknologi desain serta dukungan teknologi informasi (TI) dalam model dan desain dianggap penting dan merupakan merupakan peluang dalam pengembangan industri produk tekstil.

\section{Analisis Industri Porter's Five Forces}

\section{Persaingan Industri Pakaian Olah Raga}

Persaingan indutri pakaian olah raga merupakan ancaman meliputi banyaknya jumlah pengusaha trainingspak, persaingan harga jual produk sangat ketat, persaing aktif dalam pemasaran, pesaing melakukan inovasi produk dan tingkat produktivitas tenaga kerja. Untuk persaingan perolehan bahan baku kain tidak terlalu berpengaruh terhadap perusahaan karena PT PS memproduksi kain sendiri. Demikian juga diferensiasi bahan baku kurang berpengaruh karena jenis yang digunakan PT PS merupakan jenis kain polyester yang mutu dan harganya di bawah jenis kain lainnya, sehingga PT PS dapat menjual produk lebih murah dibanding pesaingnya.

\section{Pendatang Baru}

Hasil wawancara dengan responden menunjukkan bahwa untuk memasuki industri trainingspak sekelas PT PS sangat dipengaruhi oleh skala ekonomi, kekuatan modal, kebutuhan modal, akses terhadap saluran distribusi dan loyalitas pelanggan. Faktor-faktor tersebut sulit dimiliki oleh pendatang baru dan merupakan penghalang masuk ke dalam industri trainingspak, sehingga kondisi tersebut merupakan peluang bagi PT PS. Kehadiran pendatang baru menjadi ancaman apabila melakukan diferensiasi produk dan adanya dukungan dari pemerintah.

\section{Posisi Tawar Pemasok}

Posisi tawar pemasok merupakan ancaman, karena pemasok dapat menentukan harga jual benang. Namun demikian tersedianya pemasok alternatif dan biaya peralihan yang tidak terlalu besar merupakan peluang bagi PT PS. Kehadiran pemasok alternatif menyebabkan tidak terjadinya dominasi oleh pemasok lama karena para pemasok bersaing dengan cara menawarkan harga dan mempertahankan tingkat mutu produk.

\section{Posisi Tawar Pembeli}

Faktor ancaman dari poisisi tawar pembeli adalah trainingspak yang dibeli merupakan produk standar. Faktor peluang adalah (a) pembeli merupakan konsumen setingkat grosir, (b) tidak ada dominasi pembeli karena PT PS memproduksi trainingspak dalam jumlah besar dan menjual dengan harga bersaing, (c) Pembeli sulit untuk membuat training spak berharga pokok sama bahkan lebih rendah dari PT PS.

\section{Produk Substitusi}

Ketersediaan produk trainingspak yang menggunakan bahan selain polyester tersedia cukup banyak dan bervariasi, tetapi bahan tersebut harganya lebih mahal dan segmen pasarnya kalangan menengah ke atas. Hasil diskusi menentukan lima peubah peluang dan ancaman yang paling berpengaruh (Tabel 3).

Tabel 3. Daftar peluang dan ancaman

\begin{tabular}{ll}
\hline \multicolumn{1}{c}{ Peluang } & \multicolumn{1}{c}{ Ancaman } \\
\hline $\begin{array}{l}\text { Meningkatnya perminta- } \\
\text { an pasar setiap bulan } \\
\text { Agustus dan Hari Raya }\end{array}$ & $\begin{array}{l}\text { Kebijakan pemerintah } \\
\text { menarik investor luar } \\
\text { negeri di bidang } \\
\text { industri TPT }\end{array}$ \\
\hline $\begin{array}{l}\text { Trend hidup sehat } \\
\text { dengan berolah raga }\end{array}$ & Melemahnya nilai tukar \\
ID Rupiah terhadap US\$ \\
Tersedia pemasok & Terbentuknya MEA \\
alternatif & dan ACFTA \\
\hline $\begin{array}{l}\text { Pelanggan setingkat } \\
\text { grosir }\end{array}$ & $\begin{array}{l}\text { Kenaikan tarif BBM, } \\
\text { pajak dan listrik }\end{array}$ \\
\hline $\begin{array}{l}\text { Jenis kain bahan termu- } \\
\text { rah (jenis kain hyget) }\end{array}$ & Banyaknya jumlah \\
jarang digunakan untuk & training spak
\end{tabular}

\section{Tahap Masukan (The Input Stage)}

Hasil evaluasi faktor internal disajikan dalam Tabel 4 dan hasil evaluasi faktor eksternal disajikan dalam Tabel 5. Dari Tabel 4 terlihat faktor internal yang merupakan kekuatan utama perusahaan ini adalah bahan baku trainingspak dibuat sendiri $(0,443)$. Urutan kekuatan selanjutnya adalah pola produksi dilakukan dengan kemitraan menggunakan sistem maklun $(0,426)$, melakukan pemasaran regional $(0,417)$, kualitas kain seragam $(0,354)$ dan harga jual produk bersaing $(0,352)$. Urutan faktor kelemahan perusahaan yaitu belum adanya petugas khusus yang menangani mutu $(0,121)$, pencelupan dengan sistem maklun 
berbiaya tinggi karena pabrik pencelupan berada di Bandung sehingga perusahaan harus mengeluarkan biaya pengiriman dan pengambilan kain $(0,127)$, keterbatasan tenaga produksi yang terampil $(0,137)$, jarang melakukan pemeliharaan loyalitas pelanggan $(0,150)$ dan mesin tenun bekas $(0,165)$. Total skor evaluasi faktor internal adalah 2,692. Hal ini menunjukkan bahwa secara internal perusahaan berada dalam posisi diatas rataan $(2,50)$.

Dari Tabel 5 terlihat faktor eksternal yang merupakan peluang terbesar adalah tersedianya pelanggan setingkat grosir $(0,399)$, diikuti oleh meningkatnya permintaan pasar setiap bulan Agustus dan Hari Raya $(0,347)$. Urutan selanjutnya tersedianya pemasok alternatif $(0,318)$, tren hidup sehat dengan berolah raga $(0,299)$ dan yang terakhir adalah jenis bahan kaos termurah (jenis hyget) jarang digunakan untuk trainingspak $(0,258)$.

Faktor eksternal yang merupakan ancaman terbesar adalah melemahnya nilai rupiah terhadap dolar Amerika dan naiknya harga bahan bakar minyak, listrik dan pajak $(0,114)$, sedangkan ancaman selanjutnya adalah faktor kebijakan pemerintah menarik investor $(0,127)$, terbentuknya MEA dan ACFTA $(0,145)$ dan banyaknya jumlah pengusaha trainingspak $(0,217)$. Total skor evaluasi faktor eksternal adalah 2,334 atau dibawah rataan $(2,50)$, hal ini menunjukkan perusahaan belum dapat memanfaatkan peluang dan tidak dapat menghindari ancaman.

Tabel 4. Evaluasi faktor internal (IFE)

\begin{tabular}{clccc}
\hline \multicolumn{1}{c}{ No } & \multicolumn{1}{c}{ Bobtor Internal } & Rating & Skor \\
\hline $\begin{array}{c}\text { Kekuatan } \\
1\end{array}$ & Kain untuk bahan baku trainingspak diproduksi sendiri & 0,111 & 4,00 & 0,443 \\
2 & Memproduksi trainingspak dengan pola kemitraan/sistem & 0,107 & 4,00 & 0,426 \\
& maklun & & & \\
3 & Mutu kain seragam & 0,094 & 3,78 & 0,354 \\
4 & Harga jual produk bersaing & 0,099 & 3,57 & 0,352 \\
5 & Pemasaran regional & 0,104 & 4,00 & 0,417 \\
Kelemahan & & & \\
1 & Pencelupan dengan sistem maklun berbiaya tinggi & 0,127 & 1,00 & 0,127 \\
2 & Belum ada petugas QC & 0,070 & 1,74 & 0,121 \\
3 & Pemeliharaan loyalitas pelanggan jarang dilakukan & 0,086 & 1,74 & 0,150 \\
4 & Tenaga kerja produksi terampil terbatas & 0,091 & 1,52 & 0,137 \\
5 & Mesin tenun bekas & 0,109 & 1,52 & 0,165 \\
\hline & Total & $\mathbf{1 , 0 0 0}$ & & $\mathbf{2 , 6 9 2}$ \\
\hline
\end{tabular}

Tabel 5. Evaluasi faktor eksternal (EFE)

\begin{tabular}{|c|c|c|c|c|}
\hline No & Faktor Eksternal & Bobot & Rating & Skor \\
\hline \multicolumn{5}{|c|}{ Peluang } \\
\hline 1 & $\begin{array}{l}\text { Meningkatnya permintaan pasar setiap bulan Agustus dan } \\
\text { Hari Raya }\end{array}$ & 0,087 & 4,00 & 0,347 \\
\hline 2 & Tren hidup sehat dengan berolah raga & 0,089 & 3,37 & 0,299 \\
\hline 3 & Tersedia pemasok alternatif & 0,100 & 3,18 & 0,318 \\
\hline 4 & Pelanggan setingkat grosir & 0,100 & 4,00 & 0,399 \\
\hline 5 & $\begin{array}{l}\text { Jenis kain bahan kaos termurah (jenis kain hyget) jarang } \\
\text { digunakan untuk trainingspak }\end{array}$ & 0,086 & 3,00 & 0,258 \\
\hline \multicolumn{5}{|c|}{ Ancaman } \\
\hline 1 & $\begin{array}{l}\text { Kebijakan pemerintah menarik investor luar negeri di } \\
\text { bidang industri TPT }\end{array}$ & 0,111 & 1,25 & 0,127 \\
\hline 2 & Melemahnya nilai tukar ID Rupiah terhadap US Dollar & 0,097 & 1,15 & 0,111 \\
\hline 3 & Terbentuknya MEA dan ACTA & 0,110 & 1,32 & 0,145 \\
\hline 4 & Kenaikan harga BBM, pajak dan listrik & 0,099 & 1,15 & 0,114 \\
\hline \multirow[t]{2}{*}{5} & Banyaknya jumlah pengusaha training spak & 0,108 & 2,00 & 0,217 \\
\hline & Total & 1,000 & & 2,334 \\
\hline
\end{tabular}


Tahap Pemaduan (The Matching Stage)

\section{IE Matrix}

Hasil pemaduan skor EFE $(2,692)$ dan IFE $(2,334)$ dalam matrik IE menunjukkan posisi perusahaan berada dalam sel V (Gambar 3). Menurut David (2011) sel V merupakan posisi perusahaan harus dijaga dan dipertahankan melalui strategi penetrasi pasar dan pengembangan produk.

\section{SWOT Matrix}

Perumusan strategi menggunakan matriks SWOT (Tabel 6) dilakukan dengan cara memadukan faktor kunci internal dan eksternal, sehingga akan diperoleh rumusan strategi SO, ST, WO dan WT. Tabel 6 menunjukkan hasil perumusan strategi berdasarkan matrik SWOT, apabila dikelompokkan berdasarkan kesamaan dan kekemiripan strategi.

\section{Tahap Pemilihan (The Decision Stage)}

Tabel 7 menunjukkan hasil pemilihan strategi menggunakan analisis QSPM. Strategi promosi $(7,50)$ merupakan strategi yang menjadi prioritas pertama dibandingkan strategi lainnya. Promosi merupakan bentuk strategi intensif melalui penetrasi pasar. Terpilihnya strategi promosi sesuai dengan hasil analisis Internal-External (IE) yang memosisikan perusahaan harus dijaga dan pertahankan melalui strategi penetrasi pasar dan pengembangan produk.

\section{Implikasi Manajerial}

Penerapan strategi promosi oleh PT PS membawa implikasi kepada aspek: (1) Produksi perlu didukung oleh peningkatan skala ekonomi dengan peningkatan kemitraan melalui pengusaha lain, pemilihan pemasok, memanfaatkan efek pembelajaran dan pengalaman, (2) SDM perlu peningkatan keterampilan pekerja, (3) Keuangan melalui pembayaran kontan dari pembeli dan peningkatan alokasi biaya pemasaran, (4) Aspek Pemasaran melalui penentuan target pasar setingkat grosir, memperluas wilayah pemasaran dan pemeliharaan loyalitas pelanggan dan (5) Aspek Teknologi melalui restrukturisasi mesin.

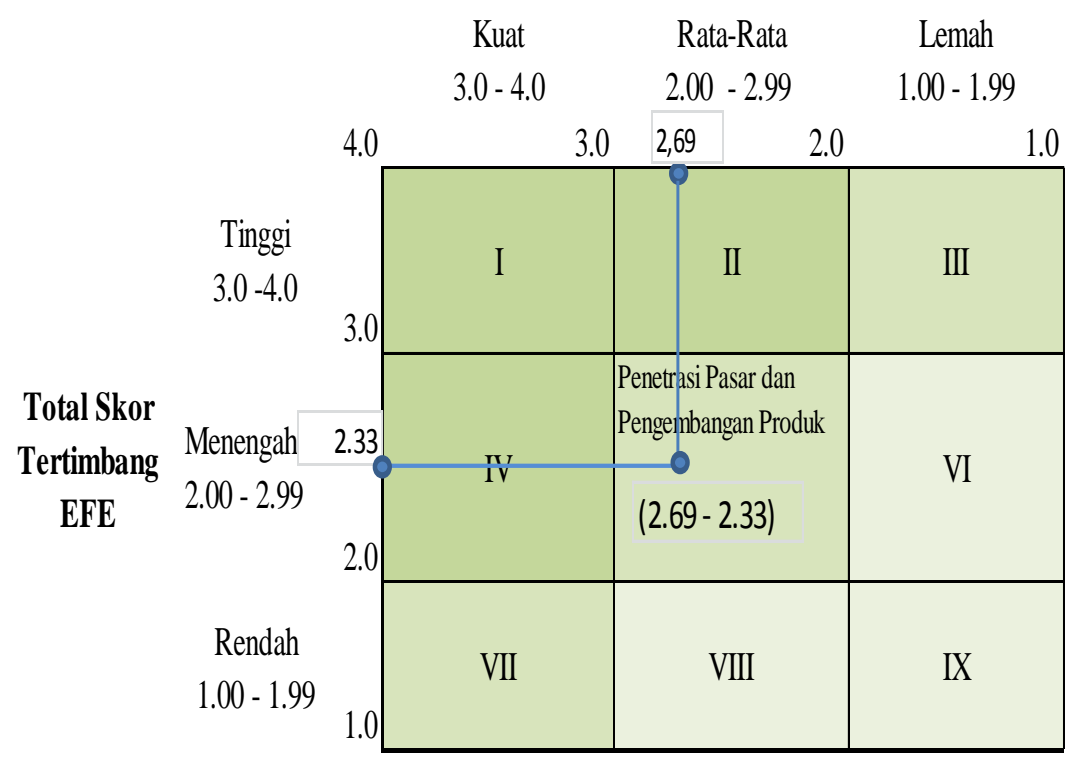

Gambar 3. Matrik Internal-Eksternal 
Tabel 6. Matriks SWOT PT PS

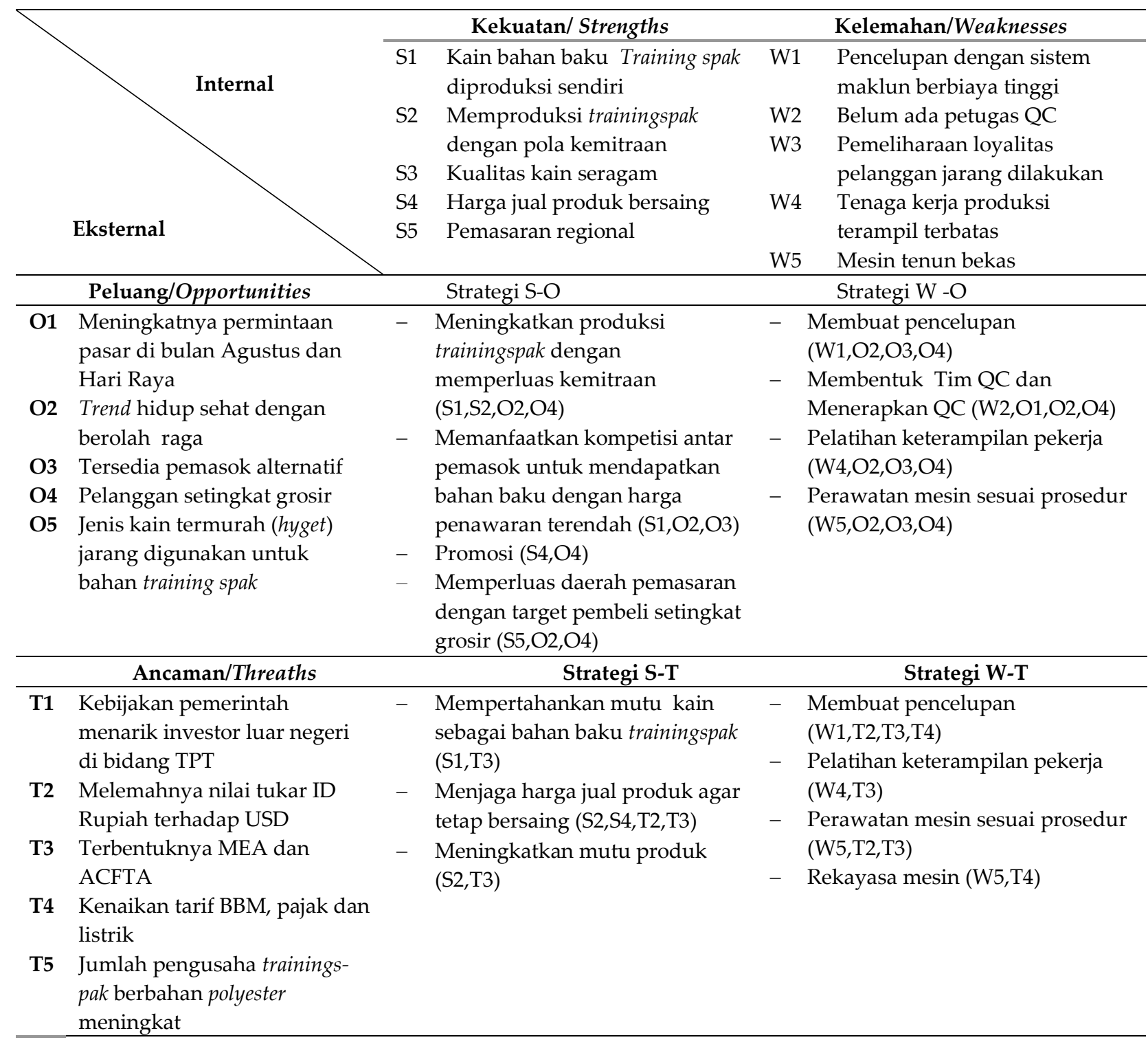

Tabel 7. Hasil analisis QSPM

\begin{tabular}{|c|c|c|}
\hline No & Prioritas Strategi & TAS \\
\hline 1 & Promosi & 7,50 \\
\hline 2 & Membuat pencelupan & 6,67 \\
\hline 3 & $\begin{array}{l}\text { Mempertahankan kualitas kain sebagai } \\
\text { bahan baku training spak }\end{array}$ & 6,59 \\
\hline 4 & Meningkatkan mutu produk & 6,40 \\
\hline 5 & $\begin{array}{l}\text { Memperluas daerah pemasaran dengan } \\
\text { target pembeli setingkat grosir }\end{array}$ & 6,21 \\
\hline 6 & $\begin{array}{l}\text { Memanfaatkan kompetisi antar pemasok } \\
\text { untuk mendapatkan bahan baku dengan } \\
\text { harga penawaran terendah }\end{array}$ & 5,73 \\
\hline 7 & $\begin{array}{l}\text { Meningkatkan produksi training spak } \\
\text { dengan memperluas kemitraan }\end{array}$ & 5,68 \\
\hline 8 & Pelatihan keterampilan pekerja & 5,58 \\
\hline 9 & $\begin{array}{l}\text { Perawatan mesin sesuai prosedur dan } \\
\text { rekayasa mesin }\end{array}$ & 4,56 \\
\hline
\end{tabular}

\section{KESIMPULAN}

1. Berdasarkan analisis faktor internal, perusahaan dalam posisi diatas rataan dalam menggunakan kekuatan dan meminimalkan kelemahan. Analisis faktor eksternal menunjukkan perusahaan berada di bawah posisi rataan dalam memanfaatkan peluang dan menghindari ancaman. Nilai matrik IE menunjukkan posisi perusahaan berada di sel $\mathrm{V}$ (jaga dan pertahankan), dapat dilakukan dengan strategi penetrasi pasar dan pengembangan produk.

2. Penggunaan matrik SWOT dalam rumusan strategi perusahaan menghasilkan 14 rumusan alternatif strategi.

3. Prioritas strategi yang dipilih berdasarkan analisis QSPM adalah strategi promosi.

(a) Keberhasilan strategi promosi dipengaruhi oleh kekuatan perusahaan untuk menjual 
produk dengan harga bersaing bahkan lebih murah dari pesaing dan tersedianya pelanggan sekelas grosir. Perusahaan dapat menentukan harga bersaing/murah karena memiliki keunggulan biaya (Overall Cost Leadership). Dengan demikian perusahaan memproduksi dengan biaya rendah sehingga dapat memberikan harga jual lebih murah dan mutu produk yang sama dibandingkan dengan pesaing yang berasal dari perusahaan sejenis di dalam negeri maupun produk impor dan dapat mendorong peningkatan pemesanan dari buyer.

(b) Kemitraan dengan pengusaha lain dengan sistem maklun dan tersedianya pilihan pemasok yang kompetitif dapat meningkatkan skala ekonomi sehingga dapat mengatasi masalah kenaikan upah dan kenaikan harga bahan baku.

\section{DAFTAR PUSTAKA}

Asmara, A., YL. Purnamadewi, A. Meiri. 2014. Struktur Biaya Industri dan Pengaruhnya Terhadap Kinerja Industri Tekstil dan Produk Tekstil Indonesia. Jurnal Manajemen dan Agribisnis [internet] [diunduh 2016 Okt24];11(2).

http://journal.ipb.ac.id/index.php/jmagr/arti cle/view/8452/7113

[API] Asosiasi Pertekstilan Indonesia (ID). 2014. Industri Garment. Jakarta (ID). API.

[BPS] Badan Pusat Statistik (ID). 2015. Statistik Indonesia Tahun 2015. Jakarta(ID). Badan Pusat Statistik.

[BPS] Badan Pusat Statistik (ID). 2014. Penyajian Data dan Informasi Kepemudaan dan Keolahragaan. Jakarta (ID). Badan Pusat Statistik.

[BPS] Badan Pusat Statistik (ID). 2012. Sensus Penduduk tahun 2010.Jakarta (ID). Badan Pusat Statistik

Badan Pusat Statistik [BPS] Badan Pusat Statistik Kota Tasikmalaya. (ID) 2016 PDRB Kota Tasikmalaya 2014. Tasikmalaya (ID). Badan Pusat Statistik Kota Tasikmalaya.
Barney, JB. 1991. Firm Resources and Sustained Competitive Advantage. Journal of Management. 17(1): 99-120.

David, FR. 2011. Strategic Management. Consepts and Cases. 13th ed. New Jersey (US). Prentice Hall.

[Diskop, UMKM \& Indag] Dinas Koperasi, UMKM, Perindustrian dan Perdagangan Kota Tasikmalaya, 2016. Rekapitulasi Data Potensi Industri Tahun 2009-2015.

Gupta, A. 2013. Environmental and PEST Analysis: An approach to external business environment. IJMSS. 2(1):34-43.

Hamel, G. and CK. Prahalad. 2005. Strategic Intent. Harvard BusinessReview [Internet] [Diunduh 2016 Agu 9]. https://hbr.org/2005/07/strategic-intent\# http://www.foundationforeuropeanleaders hip.org/assets/downloads/infoItems/148.pdf

Hansen, DR. dan MM. Mowen. 2001. Manajemen Biaya: akuntansi dan pengendalian. Ambarriani AA, penerjemah. Jakarta (ID). Salemba Empat. Terjemahan dari: Cost Management, accounting and control.

Hubeis, M. dan M. Najib. 2014. Manajemen Strategik dalam Pengembangan Daya Saing Organisasi. Jakarta (ID). Elex Media Komputindo

Irawan, H. dan R. Suryatoga. 2009. Analisis Rantai Nilai Tekstil dan Produk Tekstil di Indonesia. JMI. 9 (3).

Pearce, II JA and RB. Robinson Jr. 2014. Manajemen Strategis, ed (12). Jakarta (ID). Salemba Empat.

Rangkuti, F. 2014. Analisa SWOT Teknik Membedah Kasus Bisnis. Jakarta (ID). Gramedia Pustaka Utama.

Ririh, KR., A. Anggrahini dan Amalia. 2011 Sep. Srategi Kebijakan Pengembangan dan Pembinanaan IKM. J@tiUndip.6(3):179-188.

Shank, JK. and V. Govindarajan. 1992. Strategic Cost Management: The Value Chain Perspective. Journal of Management Accounting Research (4): 179-197.

Wheelen, TL. and JD. Hunger. 2012. Strategic Managment Business Policy. 13 th Ed. Upper Saddle River New Jersey. Prenctice Hall. 